\title{
Dietary intake and urinary excretion of lignans in Finnish men
}

\author{
Tarja Nurmi $^{1 *}$, Jaakko Mursu ${ }^{1}$, José L. Peñalvo ${ }^{2}$, Henrik E. Poulsen ${ }^{3}$ and Sari Voutilainen ${ }^{1,4}$ \\ ${ }^{1}$ Research Institute of Public Health, School of Public Health and Clinical Nutrition, University of Kuopio, PO Box 1627, FI-70211 \\ Kuopio, Finland \\ ${ }^{2}$ Department of Cardiovascular Epidemiology and Population Genetics, CNIC, 28029-Madrid, Spain \\ ${ }^{3}$ Laboratory of Clinical Pharmacology Q7642, Faculty of Health Sciences, University of Copenhagen, Rigshospitalet, Blegdamsvej \\ 9, DK-2100 Copenhagen, Denmark \\ ${ }^{4}$ Department of Clinical Nutrition, School of Public Health and Clinical Nutrition, University of Kuopio, FI-70211 Kuopio, Finland \\ (Received 31 March 2009 - Revised 12 August 2009 - Accepted 3 September 2009 - First published online 8 October 2009)
}

Intake of lignans has been assessed in different study populations, but so far none of the studies has compared the daily intake of lignans and the urinary excretion of plant and enterolignans. We assessed the intake of lariciresinol, pinoresinol, secoisolariciresinol and matairesinol in 100 Finnish men consuming their habitual omnivorous diet, and measured the $24 \mathrm{~h}$ urinary excretion of plant and enterolignans to compare the intake and metabolism. Dietary determinants of lignan intake and their urinary excretion were also determined. The mean intake of lignans was 1224 (SD 539) $\mu \mathrm{g} / \mathrm{d}$, of which lariciresinol and pinoresinol covered $78 \%$. Almost half (47\%) of the intake of lignans was explained by the intake of rye products, berries, coffee, tea and roots. The urinary excretion of plant lignans corresponded to $17 \%$ and enterolignans to $92 \%$ of the intake of lignans. The urinary excretion of plant lignans was explained $14 \%$ by the intake of rye products and intake of coffee, and consequently $3-7 \%$ by the intake of water-insoluble fibre. The urinary excretion of enterolactone was explained $11 \%$ by the intake of vegetables and rye products, $14 \%$ by the intake of water-soluble fibre and only $4 \%$ by the intake of lariciresinol. Although the assessed intake of lignans corresponded well with the urinary excretion of lignans, the enterolactone production in the human body depended more on the dietary sources of lignans than the absolute intake of lignans.

Lignans: Enterolactone: Diet: Urine

Lignans are phenolic compounds widely distributed in the plant kingdom ${ }^{(1)}$. It has been long assumed that only two plant lignans, secoisolariciresinol and matairesinol, are the dietary precursors of enterolactone and enterodiol (enterolignans), lignan metabolites that are produced after intestinal fermentation in humans ${ }^{(2)}$. It is now known that secoisolariciresinol and matairesinol are not the only dietary precursors of enterolignans ${ }^{(3,4)}$, and other plant lignans, such as lariciresinol and pinoresinol, are converted to enterolignans ${ }^{(5)}$. High serum enterolactone concentrations have been associated with a reduced risk of breast cancer ${ }^{(6)}$ and $\mathrm{CVD}^{(7)}$, but also several studies have not observed any associations ${ }^{(8,9)}$, which has caused debate on the role of enterolactone ${ }^{(10)}$.

Dietary intake of lignans was first assessed by using the data only for secoisolariciresinol and matairesinol ${ }^{(11-13)}$, and the intake varied from 175 to $991 \mu \mathrm{g} / \mathrm{d}^{(13-18)}$. After an analytical method was developed to measure also lariciresinol and pinoresinol in foods ${ }^{(19)}$, an updated database was developed for lignans in different Dutch foods ${ }^{(20)}$, and subsequently intakes of lariciresinol and pinoresinol in addition to secoisolariciresinol and matairesinol were for the first time reported in a Dutch study population ${ }^{(21)}$. The mean or median intake of the four lignans has been approximately $1000 \mu \mathrm{g} / \mathrm{d}$ in the Dutch, French and Canadian studies ${ }^{(6,21,22)}$. Analytical methods for measuring food lignans are usually developed so that they give the highest possible yield for each analyte ${ }^{(19,23)}$, which may lead to overestimation of the lignan intake.

Correlation between daily grain product intake $(\mathrm{kJ} / \mathrm{d})$ and $24 \mathrm{~h}$ urinary excretion of enterolactone has been calculated to be 0.996 , indicating that cereal foods are important sources of plant lignans, which can be metabolised to enterolactone ${ }^{(24)}$. Several studies have reported the intake of wholegrain products to be the most important determinant of serum enterolactone ${ }^{(25-27)}$, but also coffee, tea and alcohol affect the serum enterolactone concentrations ${ }^{(21,26)}$. The urinary excretion of enterolignans has been reported as 2.0 and $17.7 \mu \mathrm{mol} / \mathrm{d}$ in American omnivores and macrobiotics, respectively ${ }^{(24)}$. More recently the urinary excretion of enterolactone has been reported to be $18.4 \mu \mathrm{mol} / \mathrm{d}$ in Danish women $^{(28)}, 23.9 \mu \mathrm{mol} / \mathrm{d}$ in French women and men ${ }^{(29)}$, and $2.5 \mu \mathrm{mol} / \mathrm{d}$ in Finnish women and men ${ }^{(24,30)}$. The urinary excretion of different plant lignans has been reported, after they were identified ${ }^{(31)}$. Quantitative results for urinary plant lignans have been reported only for matairesinol ${ }^{(32)}$, except in the method development paper ${ }^{(33)}$. So far none of the studies has reported the daily intake of plant lignans and the urinary excretion of plant and enterolignans. Therefore it is unclear how well the calculated intake of plant lignans 
corresponds to the urinary excretion, and on the other hand it is not known whether the intake of lignans would explain the production of enterolignans.

The aim of the present study was to assess the intake of lariciresinol, pinoresinol, secoisolariciresinol and matairesinol in Finnish men, to compare the intake of lignans with the urinary excretion of plant and enterolignans, and to study the dietary determinants of lignan intake and their urinary excretion.

\section{Materials and methods}

\section{Study settings and population}

The present study population was a subset of the participants in the Antioxidant Supplementation in Atherosclerosis Prevention (ASAP) study ${ }^{(34)}$. The ASAP study is a balanced $2 \times 2$ factorial double-masked placebo-controlled randomised clinical trial to study the effects of vitamin $\mathrm{C}$ and $\mathrm{E}$ supplementation on oxidative stress, lipid peroxidation and atherosclerotic progression in human subjects. The present study was conducted according to the guidelines laid down in the Declaration of Helsinki and all procedures involving human subjects were approved by the Research Ethics Committee, Hospital District of Northern Savo. Written informed consent was obtained from all subjects. From 256 male participants, a subsample of 100 consecutive men aged 58.6 (SD 6.5) years was selected for the lignan intake study ${ }^{(35)}$. All data and samples used for the present study were collected at the baseline visit between April and October 1995 before any vitamin supplementation. Subjects collected $24 \mathrm{~h}$ urine sample during the preceding day of the study visit. One of the subjects took antibiotics in the preceding 6 months. The total volume of the urine sample was determined and samples were stored first at $-70^{\circ} \mathrm{C}$ and later at $-20^{\circ} \mathrm{C}$ until lignans were analysed.

\section{Assessment of food and nutrient intake}

The consumption of foods was assessed at the study baseline with an instructed $4 \mathrm{~d}$ food recording by household measures. The instructions were given and the completed food records were checked by a nutritionist. Subjects were asked to abstain from alcohol for 1 week before the laboratory visit, and alcohol consumption was recorded from a questionnaire inquiring year-round consumption. The intakes of nutrients were calculated using NUTRICA ${ }^{\circledR}$ software (version 2.5; National Public Health Institute, Turku, Finland $)^{(36)}$. The contents of lariciresinol, pinoresinol, secoisolariciresinol and matairesinol in foods were entered into the database. The assessment of lignan intake was mainly based on the lignan contents of foods reported by Milder et al. ${ }^{(20)}$ for The Netherlands. For flours we used the values published by Smeds et al. ${ }^{(37)}$ and the lignan contents of different berries were analysed from frozen berry samples (Table 1). Values for foods containing lignans less than $10 \mu \mathrm{g} / 100 \mathrm{~g}$ fresh weight were not considered. Altogether the lignan contents of 110 foodstuffs (twenty-nine cereal foods, fifty-six vegetables, fruits and berries, and twenty-five other foods, for example, coffee and tea) commonly consumed by the Finnish population were entered into the database. On the basis of these values, the lignan content of mixed dishes was calculated.

The above-mentioned foods containing lignans were grouped as: wholegrain products (including rye products), rye products, rice, pasta, vegetables, roots, potatoes, pulses, nuts, fruits, berries, fruit juices, berry juices, jam, coffee, and tea. In more detail, the wholegrain products included different breads, flakes, bran, germ and muesli products, excluding refined flour products. The rye products contained different rye breads, rye flour, flakes, bran and malt. The rice and pasta groups included both wholegrain and refined products, and they were not included in the wholegrain products. The vegetable group included all fresh and frozen vegetables, excluding pickled and canned vegetables. The roots (most commonly consumed in Finland are carrots, Swedish turnip (swede), turnip and beetroot) included all roots, except potatoes which were grouped into a separate variable. The fruits included fresh, canned and dried fruits and fruit nectars, while other juices were included in the fruit juices. The berries included all fresh and frozen berries, crushed lingonberries and lingonberry jam, which in Finland are usually prepared without sugar. Other preserved berry and fruit products were grouped into the jam variable and berry juices into their own variable. The coffee and tea variables included these drinks, and the lignan content of a drink was entered as that in the brewed drink.

\section{Lignan analyses of berries and breads}

Lignans in Finnish berries and rye breads were analysed with HPLC using coulometric electrode array detection. The sample pretreatment for berries and breads was modified

Table 1. Lignan content of different berries ( $\mu \mathrm{g} / 100 \mathrm{~g}$ fresh weight)

\begin{tabular}{|c|c|c|c|c|c|}
\hline Berries & Lariciresinol & Pinoresinol & Secoisolariciresinol & Matairesinol & Total \\
\hline Strawberry (Dutch) (Fragaria $\times$ ananassa) & 117 & 212 & 5 & nd & $334^{*}$ \\
\hline Bilberry (Vaccinium myrtillus) & 41 & 59 & 14 & nd & 114 \\
\hline Raspberry (Rubus idaeus) & 13 & 142 & 11 & nd & 166 \\
\hline Lingonberry (Vaccinium vitis-idaea) & 19 & 586 & 140 & nd & 745 \\
\hline Cranberry (Vaccinium oxycoccus) & 69 & 122 & 193 & nd & 384 \\
\hline Cloudberry (Rubus chamaemorus) & 166 & 54 & 12 & nd & 232 \\
\hline Redcurrant (Ribes rubrum) & 20 & 0 & 36 & nd & 56 \\
\hline Blackcurrant (Ribes nigrum) & 0 & 0 & 109 & nd & 109 \\
\hline Gooseberry (Ribes uva-crispa) & 10 & 30 & 82 & nd & 122 \\
\hline Sea buckthorn (Hippophae rhamnoides) & 33 & 0 & 6 & nd & 39 \\
\hline
\end{tabular}

nd, Not detected.

* From Milder et al. ${ }^{(20)}$ 
from the method published by Peñalvo et al. ${ }^{(23)}$, and modifications were described by Penttinen-Damdimopoulou et al. ${ }^{(38)}$. The lignan contents of the four above-mentioned lignans (lariciresinol, pinoresinol, secoisolariciresinol and matairesinol) in the Finnish rye breads were similar to those reported by Milder et al. ${ }^{(20)}$, and therefore the Dutch values for breads were used for consistency. The Dutch values for strawberries were higher than those reported by others ${ }^{(39,40)}$, but again the Dutch values were used to minimise the effects of different analytical methods on the results. For the other berries, lignan contents were determined in our laboratory (Table 1). Lower values have been previously published for the four lignans in raspberries, blackcurrants and blueberries ${ }^{(39)}$. In sea buckthorn only secoisolariciresinol and matairesinol have been determined ${ }^{(41)}$, but their sum was close to our value, although we detected lariciresinol instead of matairesinol.

\section{Analysis of urinary plant and enterolignans, and serum enterolactone}

Analysed lignans were secoisolariciresinol, matairesinol, pinoresinol, lariciresinol, syringaresinol, isolariciresinol, enterolactone and enterodiol. Molecular structures and metabolic pathways of these lignans are presented in Fig. 1. The urinary lignans were analysed using HPLC with a coulometric electrode array detector (HPLC-CEAD). Sample pretreatment and chromatographic conditions for urinary lignans have been described in detail previously ${ }^{(33)}$. Serum enterolactone concentrations were determined with the time-resolved fluoroimmunoassay method as described previously in detail ${ }^{(42)}$.

\section{Statistical methods}

Statistical analyses were carried out with SPSS statistical software (version 14.0 for Windows; SPSS, Inc., Chicago, IL,
USA). The intake of lignans and the urinary excretion of lignans were logarithmically transformed to improve normality. A stepwise linear regression analysis was used to determine the foods explaining the intake of lignans, and foods and nutrients explaining the urinary excretion of lignans. Changes for $R^{2}$, adjusted $R^{2}$ values of the models and standardised regression $\beta$ coefficients were reported for the determinants. The size of the study population was divided by the median urinary excretion of enterolactone, and the means between the groups were compared with ANOVA.

\section{Results}

\section{Intake of lignans and their dietary determinants}

The mean intake of the four plant lignans was 1224 (SD 539) $\mu \mathrm{g} / \mathrm{d}$ (median $1162 \mu \mathrm{g} / \mathrm{d}$; range $250-989 \mu \mathrm{g} / \mathrm{d}$ ), of which lariciresinol represented $40 \%$, pinoresinol $38 \%$, secoisolariciresinol $14 \%$ and matairesinol $7 \%$ (Table 2). Almost half $(47 \%)$ of the intake of lignans was explained by the intake of rye products, berries, coffee, tea and roots (Table 3). More than half of the intake of lariciresinol $(55 \%)$ and pinoresinol $(51 \%)$ was explained by the intake of wholegrain products, coffee, berries, and tea, but the intake of secoisolariciresinol $(57 \%)$ was explained mainly by the intake of coffee and tea. Only $13 \%$ of the intake of matairesinol was explained, and determinants were the intake of coffee and roots. The effects of rye products on the coefficients of explanation were tested separately. A few percent reduction of the coefficient of explanation for the intake of lariciresinol $(-7 \%)$ was observed, when the rye products were entered to the model, instead of the wholegrain products. The coefficients of explanation of the intake of pinoresinol, secoisolariciresinol or matairesinol were not affected. According to the results of the regression analysis, consuming daily more of<smiles>COc1cc(CC2CO[C@@H](c3ccc(O)c(OC)c3)C2CO)ccc1O</smiles>

Pinoresinol<smiles>COc1cc(CC(CO)C(CO)Cc2ccc(O)c(OC)c2)ccc1O</smiles>

Secoisolariciresinol<smiles>COc1cc(C2c3cc(O)c(OC)cc3C(CO)[C@H]2CO)ccc1O</smiles>

Isolariciresinol<smiles>COc1cc([C@@H]2OC[C@@H]3[C@H](c4cc(OC)c(O)c(OC)c4)OC[C@H]23)cc(OC)c1O</smiles>

Syringaresinol<smiles>OCC(CO)C(CO)Cc1cccc(O)c1</smiles>

Enterodiol<smiles>COc1cc(C[C@@H]2COC(=O)[C@H]2Cc2ccc(O)c(OC)c2)ccc1O</smiles>

Matairesinol<smiles>O=C1OCC(Cc2cccc(O)c2)C1Cc1cccc(O)c1</smiles>

Enterolactone

Fig. 1. Structures and metabolism of lignans. 
Table 2. Dietary intake and urinary excretion of lignans

(Mean values and standard deviations)

\begin{tabular}{|c|c|c|c|c|c|c|c|c|}
\hline \multirow[b]{2}{*}{ Lignan } & \multirow{2}{*}{$\begin{array}{l}\text { Proportion of } \\
\text { lignan intake (\%) }\end{array}$} & \multicolumn{2}{|c|}{$\begin{array}{l}\text { Intake from diet } \\
(\mu \mathrm{g} / \mathrm{d})\end{array}$} & \multicolumn{2}{|c|}{$\begin{array}{l}\text { Urinary excretion } \\
(\mu \mathrm{g} / \mathrm{d})\end{array}$} & \multicolumn{2}{|c|}{$\begin{array}{l}\text { Urinary excretion } \\
(\mu \mathrm{mol} / \mathrm{d})\end{array}$} & \multirow{2}{*}{$\begin{array}{l}\text { Proportion of } \\
\text { intake }(\%)^{*}\end{array}$} \\
\hline & & Mean & SD & Mean & SD & Mean & SD & \\
\hline Lariciresinol & 40 & 494 & 197 & 85 & 63 & 0.23 & 0.17 & 17 \\
\hline Pinoresinol & 38 & 467 & 220 & 22 & 46 & 0.06 & 0.13 & 5 \\
\hline Secoisolariciresinol & 14 & 173 & 122 & 80 & 101 & 0.22 & 0.28 & 5 \\
\hline Matairesinol & 7 & 91 & 81 & 17 & 26 & 0.05 & 0.07 & 19 \\
\hline Plant lignans & & 1224 & 539 & 204 & 175 & 0.81 & 0.69 & 17 \\
\hline Enterodiol & & - & - & 168 & 529 & 0.56 & 1.75 & \\
\hline Enterolactone & & - & - & 957 & 850 & 3.21 & 2.85 & \\
\hline Enterolignans & & & & 1125 & 999 & 3.77 & 3.35 & 92 \\
\hline Total lignans & & & & 1329 & 1064 & 4.34 & 3.48 & 109 \\
\hline
\end{tabular}

*Percentage amount of urinary excretion of the dietary intake.

either $75 \mathrm{~g}$ of rye products, $45 \mathrm{~g}$ of berries, $273 \mathrm{ml}$ of coffee or $132 \mathrm{ml}$ of tea, corresponding to regular servings, would increase the intake of lignans approximately $200 \mu \mathrm{g} / \mathrm{d}$, which is comparable with a $15-20 \%$ increase in the daily intake of lignans.

\section{Urinary excretion of lignans and their dietary determinants}

The urinary excretion of the four plant lignans corresponded to $17 \%$ of the total lignan intake, and the most extensively metabolised were pinoresinol and secoisolariciresinol, for which only $5 \%$ of the intake was detected in the urine as such (Table 2). The urinary excretion of enterolignans represented $92 \%$ of the intake of lignans. The total excretion of the four plant lignans

Table 3. Dietary determinants of lignan intake in a stepwise linear regression analysis

\begin{tabular}{cclc}
\hline Dietary lignan & $R^{2}$ change & \multicolumn{1}{c}{ Determinants ${ }^{*}$} & $\beta$ \\
\hline Plant lignanst & 0.205 & Rye products & 0.321 \\
& 0.091 & Berries & 0.370 \\
& 0.073 & Coffee & 0.444 \\
& 0.108 & Tea & 0.355 \\
Adjusted $R^{2}$ & 0.022 & Roots & 0.149 \\
Lariciresinol & 0.472 & & \\
& 0.238 & Wholegrain products & 0.397 \\
& 0.114 & Coffee & 0.462 \\
& 0.082 & Berries & 0.359 \\
& 0.100 & Tea & 0.323 \\
Adjusted $R^{2}$ & 0.028 & Roots & 0.165 \\
Pinoresinol & 0.018 & Pasta & 0.138 \\
& 0.554 & & \\
& 0.306 & Wholegrain products & 0.497 \\
Adjusted $R^{2}$ & 0.147 & Berries & 0.430 \\
Secoisolariciresinol & 0.025 & Tea & 0.275 \\
& 0.057 & Coffee & 0.268 \\
& 0.514 & & \\
& 0.409 & Coffee & 0.732 \\
& 0.082 & Tea & 0.301 \\
Adjusted $R^{2}$ & 0.050 & Pasta & 0.230 \\
Matairesinol & 0.026 & Roots & 0.167 \\
Adjusted $R^{2}$ & 0.027 & Berries & 0.166 \\
\hline & 0.572 & & \\
& 0.103 & Coffee & 0.323 \\
& 0.039 & Roots & 0.198 \\
& 0.125 & & \\
\hline
\end{tabular}

* Intake of foods, $P$ in 0.05 and out 0.10 in stepwise regression analysis. † Sum of lariciresinol, pinoresinol, secoisolariciresinol and matairesinol. and enterolignans represented $109 \%$ of the intake of lignans. In addition to urinary plant lignans presented in Table 2, also syringaresinol and isolariciresinol were analysed. The mean urinary excretion of syringaresinol and isolariciresinol were 12 (SD 23) and 78 (SD 95) $\mu \mathrm{g} / \mathrm{d}$, respectively.

The urinary excretion of the four plant lignans was explained $14 \%$ by the intake of rye products and coffee (Table 4). The highest intake of coffee $(>750 \mathrm{ml} / \mathrm{d})$ was observed in the present study among those subjects having also the highest intake of rye products $(165 v .105 \mathrm{~g} / \mathrm{d}$; $P=0.005)$, and therefore the high intake of lignans (1817 $v$. $1127 \mu \mathrm{g} / \mathrm{d} ; P<0.001)$. These subjects excreted in particular enterodiol $(1.7 v .0 .37 \mu \mathrm{mol} / \mathrm{d}, P=0.054)$, while the urinary excretion of plant lignans was lower than among the others. Consequently, the standardised $\beta$ was found to be negative for the intake of coffee as a determinant of the urinary excretion of plant lignans. The urinary excretion of lariciresinol was explained $16 \%$ by the intake of rye products, coffee and pasta. A similar coefficient of explanation was obtained for urinary isolariciresinol, and determinants were the intake of rye products, coffee and vegetables. The urinary excretion of other plant lignans was explained only a few percent by the intake of rye products or tea, and the urinary excretion of pinoresinol had no food determinants. The urinary excretion of enterolactone was explained $11 \%$ by the intake of vegetables and rye products and the urinary excretion of enterodiol by the intake of pasta. According to the results of the regression analysis, consuming daily either $64 \mathrm{~g}$ more vegetables or $75 \mathrm{~g}$ more rye products, corresponding to regular servings, would increase the urinary excretion of enterolactone approximately $0.75 \mu \mathrm{mol} / \mathrm{d}$, which corresponds to a $23 \%$ increase in the daily excretion.

\section{Intake of fibre and lignans as determinants of the urinary excretion of lignans}

The intake of vegetables and berries was significantly higher in the high-enterolactone group, and the intake of other fibre-rich foods, such as wholegrain products, rye products, and fruits, was also higher in the high-enterolactone group (Table 5). Although these differences were not significant, they were large enough to find significant discrepancies of fibre intake favourable to the high-enterolactone group. The intake of water-soluble fibre explained $14 \%$ of the 
Table 4. Dietary determinants of urinary lignan excretion in a stepwise linear regression analysis

\begin{tabular}{cclr}
\hline Urinary lignan & $R^{2}$ change & Determinants & \multicolumn{1}{c}{$\beta$} \\
\hline Plant lignanst & 0.101 & Rye products & 0.416 \\
& 0.055 & Coffee & -0.255 \\
Adjusted $R^{2}$ & 0.139 & & \\
Lariciresinol & 0.086 & Rye products & 0.410 \\
& 0.047 & Coffee & -0.276 \\
& 0.052 & Pasta & 0.230 \\
Adjusted $R^{2}$ & 0.159 & & \\
Pinoresinol & - & No determinants & - \\
Secoisolariciresinol & 0.050 & Rye products & 0.224 \\
Adjusted $R^{2}$ & 0.040 & & \\
Matairesinol & 0.126 & Rye products & 0.226 \\
Adjusted $R^{2}$ & 0.041 & & \\
Syringaresinol & 0.045 & Tea & 0.213 \\
Adjusted $R^{2}$ & 0.035 & & \\
Isolariciresinol & 0.085 & Rye products & 0.419 \\
& 0.060 & Coffee & -0.276 \\
Adjusted $R^{2}$ & 0.035 & Vegetables & 0.189 \\
Enterolactone & 0.155 & & \\
& 0.069 & Vegetables & 0.290 \\
Adjusted $R^{2}$ & 0.058 & Rye products & 0.243 \\
Enterodiol & 0.109 & & \\
Adjusted $R^{2}$ & 0.039 & Pasta & 0.198 \\
\hline
\end{tabular}

* Intake of foods, $P$ in 0.05 and out 0.10 in stepwise regression analysis. † Sum of lariciresinol, pinoresinol, secoisolariciresinol and matairesinol.

urinary excretion of enterolactone, while the intake of waterinsoluble fibre explained $3-7 \%$ of the urinary excretion of enterodiol and plant lignans secoisolariciresinol and isolariciresinol (Table 6). The intake of fibre, in general, explained $12 \%$ of the urinary excretion of plant lignans, and $9 \%$ of the urinary excretion of lariciresinol. The intake of lignans in the high-enterolactone group differed from that of the low-enterolactone group only by $176 \mu \mathrm{g} / \mathrm{d}$, but the urinary excretion of enterolignans differed $1300 \mu \mathrm{g} / \mathrm{d}(4.02 \mu \mathrm{mol} / \mathrm{d})$ (Table 5). Consequently, the intake of lariciresinol explained only $4 \%$ of the urinary excretion of enterolactone, $6 \%$ of the urinary excretion of lariciresinol, and $8 \%$ of the urinary excretion of plant lignans, while the intake of matairesinol explained $5 \%$ of the urinary excretion of pinoresinol (Table 6).

\section{Discussion}

The present study reported for the first time the intake of four plant lignans and their urinary excretion in the subjects consuming their habitual omnivorous diet. The intake of lignans obtained by dietary assessment corresponded well to the excreted amount of plant and enterolignans, indicating that the studied plant lignans in foods were the major enterolignan precursors in the Finnish diet. Major determinants of the lignan intake were wholegrain and rye products, berries, coffee, tea and roots. The intake of lignans was much better explained by the intake of particular foods than was explained the urinary excretion of plant and enterolignans. Major dietary determinants of the urinary excretion of lignans were the intake of rye products, coffee, vegetables and pasta. As well, the urinary excretion of plant and enterolignans was explained by the intake of fibre, but to a lesser extent by the intake of lignans, meaning that the enterolactone production depended more on the dietary sources of lignans than on the absolute intake of lignans.

The median intake of lariciresinol, pinoresinol, secoisolariciresinol and matairesinol in the present study $(1162 \mu \mathrm{g} / \mathrm{d})$ was similar to that observed in French women $(1112 \mu \mathrm{g} / \mathrm{d})^{(6)}$. A slightly lower median intake of lignans has been observed in Dutch men and women $(979 \mu \mathrm{g} / \mathrm{d})^{(21)}$ and in Canadian women $(857 \mu \mathrm{g} / \mathrm{d})^{(22)}$. The percentage contributions of lariciresinol, pinoresinol, secoisolariciresinol and matairesinol to the daily intake were very similar in the present study compared with those cited above ${ }^{(6,21)}$, although in the Canadian women the major lignan was reported to be secoisolariciresinol ${ }^{(22)}$, corresponding to flaxseed as a major source of lignans contributing as much as $88 \%$ of the total intake.

Before the knowledge of other precursors, the intake of secoisolariciresinol and matairesinol was defined as $285 \mu \mathrm{g} / \mathrm{d}$ in Finnish men ${ }^{(13)}$, corresponding well with our value $(264 \mu \mathrm{g} / \mathrm{d})$, indicating that previous results for secoisolariciresinol and matairesinol are well in line with the new values, although different study populations, methods for dietary data, and lignan contents for foods have been used. In the other studies much higher intakes for secoisolariciresinol and matairesinol have been reported, but those studies have used lignan content values of foods obtained after in vitro faecal fermentation ${ }^{(14,17)}$, which overestimates the amount of secoisolariciresinol and matairesinol in foods.

The intake of plant lignans in the present study was explained by the intake of wholegrain or rye products, berries, coffee, tea, roots and pasta, and the intake of rye products covered $75 \%$ of the daily intake of wholegrain products. The high intake of wholegrain products is a characteristic of the Finnish diet, as in the Dutch study tea and coffee contributed $30 \%$ and vegetables $24 \%$ to the intake of lignans ${ }^{(21)}$, while in the French women fruits and vegetables contributed together $66 \%$, tea $11 \%$, but the cereal foods only $7 \%(6)$. In the present study the intakes of different lignans were also explained by the intake of tea and coffee, but only the intake of secoisolariciresinol was mainly determined by coffee. The intake of tea, although low in the present study, still partly explained the intake of all lignans except matairesinol. In the Dutch study, multigrain bread was reported to be a relevant source of lignans because of its potential content of flaxseed and sesame $^{(21)}$, by far the richest sources of lignans ${ }^{(21,43)}$. In the present study subjects did not eat nuts or seeds, and at the time of the study availability of breads containing flaxseed or sesame seed was limited in Finland. This aspect, however, deserves attention in future studies. In the previous studies the intake of berries was reported together with fruits, and the separate contribution of berries to the intake of lignans could not be discerned ${ }^{(6,21)}$. In the present study the intake of berries explained the intake of plant lignans, whereas the intake of fruits, twice as much as that of berries, had no clear effect on the lignan intake. The intake of berries was before recognised as a determinant of secoisolariciresinol and matairesinol intake in Finnish men ${ }^{(13)}$, which has now been confirmed in the present study.

Although lignans have been detected in some amount almost everywhere ${ }^{(44,45)}$, the present results support previous findings indicating that lariciresinol, pinoresinol, secoisolariciresinol 
Table 5. Intake of foods, drinks and nutrients, and urinary excretion of lignans in Finnish men (Mean values and standard deviations)

\begin{tabular}{|c|c|c|c|c|c|c|c|}
\hline & & & \multicolumn{4}{|c|}{ Urinary enterolactone } & \multirow[b]{3}{*}{$P \ddagger$} \\
\hline & \multicolumn{2}{|c|}{ All } & \multicolumn{2}{|c|}{$<2.5 \mu \mathrm{mol} / \mathrm{d}^{*}$} & \multicolumn{2}{|c|}{$\geq 2.5 \mu \mathrm{mol} / \mathrm{d} \dagger$} & \\
\hline & Mean & SD & Mean & SD & Mean & SD & \\
\hline \multicolumn{8}{|l|}{ Foods and drinks } \\
\hline Wholegrain products $(\mathrm{g} / \mathrm{d})$ & 152 & 76 & 140 & 61 & 164 & 87 & 0.122 \\
\hline Rye products $(\mathrm{g} / \mathrm{d}) \S$ & 114 & 75 & 101 & 62 & 127 & 84 & 0.086 \\
\hline Pasta (g/d) & 12 & 26 & 11 & 22 & 13 & 30 & 0.719 \\
\hline Rice $(g / d)$ & 7 & 9 & 5 & 6 & 8 & 12 & 0.112 \\
\hline Vegetables (g/d) & 92 & 64 & 77 & 48 & 107 & 74 & 0.021 \\
\hline Roots $(g / d)$ & 23 & 27 & 21 & 27 & 25 & 26 & 0.442 \\
\hline Fruits $(g / d)$ & 76 & 145 & 55 & 65 & 96 & 193 & 0.163 \\
\hline Berries $(g / d)$ & 38 & 45 & 28 & 44 & 47 & 45 & 0.031 \\
\hline Coffee $(\mathrm{ml} / \mathrm{d})$ & 488 & 273 & 440 & 254 & 535 & 285 & 0.083 \\
\hline Tea $(\mathrm{ml} / \mathrm{d})$ & 65 & 132 & 67 & 117 & 64 & 147 & 0.910 \\
\hline Fruit juices (ml/d) & 34 & 98 & 28 & 94 & 40 & 102 & 0.521 \\
\hline Berry juices (ml/d) & 82 & 189 & 74 & 208 & 89 & 171 & 0.687 \\
\hline Alcohol (g/week) & 102 & 103 & 108 & 103 & 97 & 104 & 0.597 \\
\hline \multicolumn{8}{|l|}{ Nutrient intakes } \\
\hline Lignans $(\mu \mathrm{g} / \mathrm{d}) \|$ & 1224 & 539 & 1136 & 453 & 1312 & 603 & 0.104 \\
\hline Fibre $(g / d)$ & 24 & 9 & 21 & 7 & 27 & 10 & 0.001 \\
\hline Water-soluble fibre (g/d) & 5 & 2 & 5 & 1 & 6 & 2 & 0.001 \\
\hline Water-insoluble fibre $(\mathrm{g} / \mathrm{d})$ & 12 & 5 & 10 & 4 & 13 & 6 & 0.001 \\
\hline \multicolumn{8}{|l|}{ Lignans in serum and urine } \\
\hline Serum enterolactone $(\mathrm{nmol} / \mathrm{l})$ & $16 \cdot 6$ & $14 \cdot 4$ & $7 \cdot 13$ & $6 \cdot 28$ & $26 \cdot 0$ & $14 \cdot 0$ & $<0.001$ \\
\hline Urinary enterolactone $(\mu \mathrm{mol} / \mathrm{d})$ & $3 \cdot 21$ & $2 \cdot 85$ & $1 \cdot 20$ & 0.76 & $5 \cdot 22$ & $2 \cdot 76$ & $<0.001$ \\
\hline Urinary enterodiol $(\mu \mathrm{mol} / \mathrm{d})$ & 0.56 & 1.75 & 0.37 & 0.42 & 0.74 & $2 \cdot 40$ & 0.299 \\
\hline Urinary lariciresinol $(\mu \mathrm{mol} / \mathrm{d})$ & 0.23 & 0.18 & 0.23 & 0.20 & 0.24 & 0.14 & 0.675 \\
\hline Urinary pinoresinol $(\mu \mathrm{mol} / \mathrm{d})$ & 0.06 & 0.13 & 0.05 & 0.06 & 0.07 & 0.17 & 0.382 \\
\hline Urinary secoisolariciresinol $(\mu \mathrm{mol} / \mathrm{d})$ & 0.22 & 0.28 & 0.19 & 0.23 & 0.25 & 0.32 & 0.344 \\
\hline Urinary matairesinol $(\mu \mathrm{mol} / \mathrm{d})$ & 0.05 & 0.07 & 0.04 & 0.07 & 0.05 & 0.08 & 0.617 \\
\hline Urinary syringaresinol $(\mu \mathrm{mol} / \mathrm{d})$ & 0.03 & 0.05 & 0.03 & 0.04 & 0.03 & 0.06 & 0.661 \\
\hline Urinary isolariciresinol $(\mu \mathrm{mol} / \mathrm{d})$ & 0.22 & 0.26 & 0.20 & 0.23 & 0.23 & 0.30 & 0.610 \\
\hline Urinary plant lignans $(\mu \mathrm{mol} / \mathrm{d}) \|$ & 0.57 & 0.49 & 0.52 & 0.46 & 0.61 & 0.51 & 0.317 \\
\hline
\end{tabular}

* Low-enterolactone group in the text.

† High-enterolactone group in the text.

$\ddagger P$ for ANOVA.

$\S$ Included in wholegrain products.

|l Sum of lariciresinol, pinoresinol, secoisolariciresinol and matairesinol.

and matairesinol are the main enterolignan precursors in a regular, non-supplemented diet. Even though syringaresinol and medioresinol have been found in high concentrations in cereals, in particular rye ${ }^{(23,37)}$, the present results suggest that a minor fraction of them is metabolised to enterolactone. Otherwise, a larger difference between the intake and $24 \mathrm{~h}$ urinary excretion of lignans would have been observed, because the amount of syringaresinol alone in rye is almost as high as the amount of plant lignans included to the assessment of intake. Indeed, the metabolism of syringaresinol to enterolactone has been shown to be ineffective ${ }^{(5)}$, but a possible biological action of this abundant lignan deserves further investigation.

The urinary excretion of plant lignans and enterolactone was explained by the intake of rye products, but not by wholegrain products, although rye products represented $75 \%$ of the intake of wholegrain products. The highest intake of rye products was observed among the heavy coffee drinkers, and they also excreted more enterodiol, but not enterolactone. The high urinary excretion of enterodiol might occur due to a high intake of fibre shortening the transit time, and thus decreasing the effective fermentation time reported to increase serum enterolactone $^{(25)}$, although the coffee itself does not decrease the transit time ${ }^{(46)}$. The urinary excretion of enterolactone and isolariciresinol was explained by the intake of vegetables, which has been found to be a determinant of serum enterolactone concentration ${ }^{(25-27)}$ and to contribute to the lignan intake $^{(6,21)}$. The urinary excretion of pinoresinol had no food determinants at all, and it was one of the most extensively metabolised plant lignans. This observation was in line with the previously suggested metabolic pathway (Fig. 1) ${ }^{(5)}$ later confirmed $^{(47)}$.

The mean urinary excretion of enterolactone in the present study $(3.2 \mu \mathrm{mol} / \mathrm{d})$ was between the values observed before in Finnish omnivorous and lacto-vegetarian women ${ }^{(24)}$, but lower than the mean urinary excretion in French men and women $(23.9 \mu \mathrm{mol} / \mathrm{d})^{(29)}$, despite the similar lignan intake in both studies. The intake of lignans in the present study was mainly due to a high intake of cereal products containing water-insoluble fibre in contrast to vegetables, fruits and beverages which were major sources of lignans in the French and Dutch populations ${ }^{(6,21)}$. Indeed, in the present study the urinary excretion of enterolactone was explained by the intake of water-soluble fibre, while the urinary 
Table 6. Intake of fibre and different lignans as determinants of the urinary excretion of lignans in a stepwise linear regression analysis

\begin{tabular}{|c|c|c|c|}
\hline Urinary lignan & $R^{2}$ change & Determinants* & $\beta$ \\
\hline $\begin{array}{l}\text { Plant lignans } \dagger \\
\text { Adjusted } R^{2}\end{array}$ & $\begin{array}{l}0.126 \\
0.117\end{array}$ & Fibre & 0.355 \\
\hline $\begin{array}{l}\text { Plant lignanst } \\
\text { Adjusted } R^{2}\end{array}$ & $\begin{array}{l}0.090 \\
0.082\end{array}$ & Lariciresinol & 0.302 \\
\hline $\begin{array}{l}\text { Lariciresinol } \\
\quad \text { Adjusted } R^{2}\end{array}$ & $\begin{array}{l}0.101 \\
0.092\end{array}$ & Fibre & 0.318 \\
\hline $\begin{array}{l}\text { Lariciresinol } \\
\quad \text { Adjusted } R^{2}\end{array}$ & $\begin{array}{l}0.071 \\
0.061\end{array}$ & Lariciresinol & 0.266 \\
\hline $\begin{array}{l}\text { Pinoresinol } \\
\quad \text { Adjusted } R^{2}\end{array}$ & $\begin{array}{l}0.058 \\
0.048\end{array}$ & Matairesinol & 0.241 \\
\hline $\begin{array}{l}\text { Secoisolariciresinol } \\
\text { Adjusted } R^{2}\end{array}$ & $\begin{array}{l}0.083 \\
0.073\end{array}$ & Water-insoluble fibre & 0.287 \\
\hline $\begin{array}{l}\text { Secoisolariciresinol } \\
\text { Adjusted } R^{2}\end{array}$ & $\begin{array}{l}0.061 \\
0.052\end{array}$ & Plant lignans $†$ & 0.248 \\
\hline $\begin{array}{l}\text { Matairesinol } \\
\text { Syringaresinol }\end{array}$ & $\begin{array}{l}- \\
-\end{array}$ & $\begin{array}{l}\text { No determinants } \\
\text { No determinants }\end{array}$ & - \\
\hline $\begin{array}{r}\text { Syringaresinol } \\
\text { Isolariciresinol } \\
\text { Adjusted } R^{2}\end{array}$ & $\begin{array}{c}- \\
0.080 \\
0.071\end{array}$ & Water-insoluble fibre & 0.284 \\
\hline $\begin{array}{l}\text { Enterolactone } \\
\quad \text { Adjusted } R^{2}\end{array}$ & $\begin{array}{l}0.151 \\
0.142\end{array}$ & Water-soluble fibre & 0.388 \\
\hline $\begin{array}{l}\text { Enterolactone } \\
\quad \text { Adjusted } R^{2}\end{array}$ & $\begin{array}{l}0.054 \\
0.044\end{array}$ & Lariciresinol & 0.232 \\
\hline $\begin{array}{l}\text { Enterodiol } \\
\quad \text { Adjusted } R^{2}\end{array}$ & $\begin{array}{l}0.042 \\
0.032\end{array}$ & Water-insoluble fibre & 0.204 \\
\hline
\end{tabular}

* Intake of fibre or lignans, $P$ in 0.05 and out 0.10 in stepwise regression analysis. † Sum of lariciresinol, pinoresinol, secoisolariciresinol and matairesinol.

excretion of enterodiol and different plant lignans was explained by the intake of water-insoluble fibre, or fibre in general. According to these observations the urinary excretion of enterolactone, i.e. lignan metabolism, depends to some extent on the absolute intake of lignans, but more strongly on the dietary sources of lignans. The conversion of enterodiol to enterolactone was less efficient in the low-enterolactone group in contrast to the high-enterolactone group, indicating the lower activity, or lack of appropriate colon microflora ${ }^{(47)}$. Antibiotics, which have been shown to affect enterolactone production for several months ${ }^{(48,49)}$, were taken before the study only by one of the subjects who excreted enterodiol, but hardly any enterolactone.

Although the intake of lignans and their urinary excretion corresponded well, there are some limitations in the present study. The intake of lignans in Finnish men was calculated by using mainly the lignan contents for Dutch foods. In addition to geographical differences in foods, lignan contents of foods are also affected, for example, by climate, site of growth and plant variety ${ }^{(20)}$. However, we compared the lignan content of Finnish rye breads with the values presented for the Dutch breads ${ }^{(20)}$, and observed similar concentrations in both products. The assessment of lignan intake was carried out by using $4 \mathrm{~d}$ food recording, the content of which may depend on the season in Finland. For example, intake of berries and vegetables might be higher during the summer season in contrast to winter, and the present study population included subjects only from April till October. However, this possible overestimation of the intake of lignans does not seem to be relevant, since the intake of secoisolariciresinol and matairesinol corresponded to the values presented before for Finnish men ${ }^{(13)}$. The urine samples in the present study were stored 12 years before the lignan analyses.
Separate data on the stability of lignans in urine have not been published, but plant and enterolignans are quite stable at least at high temperature, in acid, and base, which are regularly applied for the sample pretreatment in food lignan methods $^{(19,23,37,44)}$. In addition to the possible effects of storage time and conditions, urinary excretion of lignans varies from day to day, depending on diet and variations in the activity of colon microflora ${ }^{(30)}$. Food recording and $24 \mathrm{~h}$ urine sample collection in the present study were not matched by time, which might cause some discrepancy to the present results. Despite all of these above-mentioned methodological limitations, the intake of lignans corresponded well to the urinary excretion of lignans, which we believe cannot be pure coincidence.

In the present study the intake of lignans (lariciresinol, pinoresinol, secoisolariciresinol and matairesinol) in Finnish men compares to the urinary excretion of plant and enterolignans, and consumed plant lignans undergo extensive metabolism in the body resulting in mainly one compound, enterolactone. A relevant fraction of plant lignans, however, is absorbed intact or only partially metabolised. The urinary excretion of enterolactone, indicating the efficiency of lignan metabolism, depended more on the dietary sources of lignans than on the absolute intake of lignans. In the future, the associations between the intake of lignans or the body enterolactone concentrations and a risk of chronic diseases should be studied in the same study population to find out whether enterolactone production as such has relevance or does the diet alone count more.

\section{Acknowledgements}

The study was financially supported by the Academy of Finland (grant no. 114526 to T. N.).

T. N. presented the original study aim, participated in food database production, carried out the data analyses and been the corresponding author during the writing process. J. M. has participated in food database production, data analyses and the writing process. J. L. P. has participated in the interpretation of data and the writing process. H. E. P. has been a principal investigator of the Antioxidant Supplementation in Atherosclerosis Prevention (ASAP) study and has participated in the writing process. S. V. has been responsible for the database production, assessment of food and nutrient intake, and participated in the writing process.

There are no conflicts of interest.

\section{References}

1. Ward RS (1993) Lignans, neolignans, and related compounds. Nat Prod Rep 10, 1-28.

2. Axelson M, Sjövall J, Gustafsson BE, et al. (1982) Origin of lignans in mammals and identification of a precursor from plants. Nature 298, 659-660.

3. Thompson LU, Robb P, Serraino M, et al. (1991) Mammalian lignan production from various foods. Nutr Cancer 16, 43-52.

4. Mazur WM (1998) Phytoestrogen content in foods. In Baillière's Clinical Endocrinology and Metabolism: Phytooestrogens, pp. 729-742 [H Adlercreutz, editor]. London: Baillière Tindall.

5. Heinonen S, Nurmi $\mathrm{T}$, Liukkonen $\mathrm{K}$, et al. (2001) In vitro metabolism of plant lignans: new precursors of mammalian 
lignans enterolactone and enterodiol. J Agric Food Chem 49 3178-3186.

6. Touillaud MS, Thiebaut ACM, Fournier A, et al. (2007) Dietary lignan intake and postmenopausal breast cancer risk by estrogen and progesterone receptor status. J Natl Cancer Inst 99, 475-486.

7. Vanharanta M, Voutilainen S, Rissanen TH, et al. (2003) Risk of cardiovascular disease-related and all-cause death according to serum concentrations of enterolactone. Arch Intern Med 163, 1099-1104.

8. Kilkkinen A, Virtamo J, Vartiainen E, et al. (2004) Serum enterolactone concentration is not associated with breast cancer risk in a nested case-control study. Int J Cancer 108, 277-280.

9. Kuijsten A, Bueno-de-Mesquita HB, Boer JMA, et al. (2009) Plasma enterolignans are not associated with nonfatal myocardial infarction risk. Atherosclerosis 203, 145-152.

10. Adlercreutz H (2007) Lignans and human health. Crit Rev Clin Lab Sci 44, 483-525.

11. Pillow PC, Duphorne CM, Chang S, et al. (1999) Development of a database for assessing dietary phytoestrogen intake. Nutr Cancer 33, 3-19.

12. Horn-Ross PL, Barnes S, Lee M, et al. (2000) Assessing phytoestrogen exposure in epidemiological studies: development of a database (United States). Cancer Causes Control 11, 289-298.

13. Valsta LM, Kilkkinen A, Mazur W, et al. (2003) Phyto-oestrogen database of foods and average intake in Finland. $\mathrm{Br} \mathrm{J} \mathrm{Nutr}$ 89, S31-S38.

14. de Kleijn MJJ, van der Schow YT, Wilson PWF, et al. (2002) Dietary intake of phytoestrogens is associated with a favorable metabolic cardiovascular risk profile in postmenopausal U.S. women: the Framingham study. J Nutr 132, 276-282.

15. Horn-Ross PL, Lee M, John EM, et al. (2000) Sources of phytoestrogen exposure among non-Asian women in California, USA. Cancer Causes Control 11, 299-302.

16. van Erp-Baart M-AJ, Brants HAM, Kiely M, et al. (2003) Isoflavone intake in four different European countries: the VENUS approach. Br J Nutr 89, Suppl. 1, S25-S30.

17. Keinan-Boker L, van Der Schouw YT, Grobbee DE, et al. (2004) Dietary phytoestrogens and breast cancer risk. Am J Clin Nutr 79, 282-288.

18. McCann SE, Freudenheim JL, Marshall JR, et al. (2003) Risk of human ovarian cancer is related to dietary intake of selected nutrients, phytochemicals and food groups. $J$ Nutr 133, 1937-1942.

19. Milder IEJ, Arts ICW, Venema DP, et al. (2004) Optimization of a liquid chromatography-tandem mass spectrometry method for quantification of the plant lignans secoisolariciresinol, matairesinol, lariciresinol, and pinoresinol in foods. J Agric Food Chem 52, 4643-4651.

20. Milder IEJ, Arts ICW, van de Putte B, et al. (2005) Lignan contents of Dutch plant foods: a database including lariciresinol, pinoresinol, secoisolariciresinol and matairesinol. Br J Nutr 93, 393-402.

21. Milder IEJ, Feskens EJM, Arts ICW, et al. (2005) Intake of the plant lignans secoisolariciresinol, matairesinol, lariciresinol and pinoresinol in Dutch men and women. J Nutr 135, 1202-1207.

22. Cotterchio M, Boucher BA, Kreiger N, et al. (2008) Dietary phytoestrogen intake - lignans and isoflavones - and breast cancer risk (Canada). Cancer Causes Control 19, 259-272.

23. Peñalvo JL, Haajanen KM, Botting NP, et al. (2005) Quantification of lignans in food using isotope dilution gas chromatography/mass spectrometry. J Agric Food Chem 53, 9342-9347.

24. Adlercreutz H, Fotsis T, Bannwart C, et al. (1986) Determination of urinary lignans and phytoestrogen metabolites, potential antiestrogens and anticarcinogens, in urine of women on various habitual diets. J Steroid Biochem 25, 791-797.
25. Kilkkinen A, Stumpf K, Pietinen P, et al. (2001) Determinants of serum enterolactone concentration. Am J Clin Nutr 73, $1094-1100$

26. Horner NK, Kristal AR, Prunty J, et al. (2002) Dietary determinants of plasma enterolactone. Cancer Epidemiol Biomarkers Prev 11, 121-126.

27. Johansen NF, Hausner H, Olsen A, et al. (2004) Intake of whole grains and vegetables determines the plasma enterolactone concentration of Danish women. J Nutr 134, 2691-2697.

28. Hausner H, Johnsen NF, Hallund J, et al. (2004) A single measurement is inadequate to estimate enterolactone levels in Danish postmenopausal women due to large intraindividual variation. J Nutr 134, 1197-2000.

29. Mennen LI, Saphino D, Ito H, et al. (2008) Urinary excretion of 13 dietary flavonoids and phenolic acids in free-living healthy subjects - variability and possible use as biomarkers of polyphenol intake. Eur J Clin Nutr 62, 519-525.

30. Stumpf K \& Adlercreutz H (2003) Short-term variation in enterolactone in serum, 24-hour urine and spot urine and relationship with enterolactone concentrations. Clin Chem 49, 178-181.

31. Bannwart C, Adlercreutz H, Wähälä K, et al. (1989) Detection and identification of the plant lignans lariciresinol, isolariciresinol and secoisolariciresinol in human urine. Clin Chim Acta 180, 293-302.

32. Adlercreutz H, Vanderwildt J, Kinzel J, et al. (1995) Lignan and isoflavonoid conjugates in human urine. J Steroid Biochem Mol Biol 52, 97-103.

33. Nurmi T, Voutilainen S, Nyyssönen K, et al. (2003) Liquid chromatography method for plant and mammalian lignans in human urine. J Chromatogr B 798, 101-110.

34. Salonen RM, Nyyssönen K, Kaikkonen J, et al. (2003) Six-year effect of combined vitamin $\mathrm{C}$ and $\mathrm{E}$ supplementation on atherosclerotic progression The Antioxidant Supplementation in Atherosclerosis Prevention (ASAP) Study. Circulation 107, 947-953.

35. Voutilainen S, Morrow JD, Roberts LJ II, et al. (1999) Enhanced in vivo lipid peroxidation at elevated plasma total homocysteine levels. Arterioscler Thromb Vasc Biol 19, $1263-1266$.

36. Hakala P, Marniemi J, Knuts L-R, et al. (1996) Calculated vs. analysed nutrient composition of weight reduction diets. Food Chem 57, 71-75.

37. Smeds AI, Eklund PC, Sjöholm RE, et al. (2007) Quantification of a broad spectrum of lignans in cereals, oilseeds and nuts. J Agric Food Chem 55, 1337-1346.

38. Penttinen-Damdimopoulou $\mathrm{P}$, Power $\mathrm{K}$, Hurmerinta $\mathrm{T}$, et al. (2009) Dietary sources of lignans and isoflavones modulate responses to estradiol in estrogen reporter mice. Mol Nutr Food Res 53, 996-1006.

39. Thompson LU, Boucher BA, Liu Z, et al. (2006) Phytoestrogen content of foods consumed in Canada, including isoflavones, lignans, and coumestans. Nutr Cancer 54, 184-201.

40. Penalvo JL, Adlercreutz H, Ueahara M, et al. (2008) Lignan content of selected foods from Japan. J Agric Food Chem 56, 401-409.

41. Yang B, Linko A-M, Adlercreutz H, et al. (2006) Secoisolariciresinol and matairesinol of sea buckthorn (Hippophae rhamnoides L.) berries of different subspecies and harvesting times. J Agric Food Chem 54, 8065-8070.

42. Vanharanta M, Voutilainen S, Nurmi T, et al. (2002) Association between low serum enterolactone and increased plasma $\mathrm{F}_{2}$-isoprostanes, a measure of lipid peroxidation. Atherosclerosis 160, 465-469.

43. Penalvo JL, Heinonen S-M, Aura A-M, et al. (2005) Dietary sesamin is converted to enterolactone in humans. $J$ Nutr $\mathbf{1 3 5}$, $1056-1062$. 
44. Smeds AI, Willför SM, Pietarinen SP, et al. (2007) Occurrence of 'mammalian' lignans in plant and water sources. Planta 226, 639-646.

45. Kuhnle GGC, dell'Aquila C, Aspinall SM, et al. (2008) Phytoestrogen content of foods of animal origin: dairy products, eggs, meat, fish, and seafood. J Agric Food Chem 56, 10099-10104.

46. Boekema PJ, Lo B, Samsom M, et al. (2000) The effect of coffee on gastric emptying and oro-caecal transit time. Eur $J$ Clin Invest 30, 129-134.
47. Clavel T, Borrmann D, Braune A, et al. (2006) Occurrence and activity of human intestinal bacteria involved in the conversion of dietary lignans. Anaerobe 12, 140-147.

48. Setchell KDR, Lawson AM, Borriello SP, et al. (1981) Lignan formation in man - microbial involvement and possible roles in relation to cancer. Lancet ii, 4-7.

49. Kilkkinen A, Pietinen P, Klaukka T, et al. (2002) Use of oral antimicrobials decreases serum enterolactone concentration. Epidemiology 155, 472-477. 